\title{
ARAŞTIRMA / RESEARCH \\ Hepatosellüler karsinomada bridging veya downstaging sonrası karaciğer transplantasyonu ile direkt transplantasyon stratejilerinin sağkalım üzerine etkilerinin karşılaştırılması
}

Comparison of survival analysis of the bridging or downstaging and direct transplantation strategies after liver transplantation in hepatocellular carcinoma

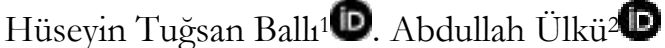 \\ ${ }^{1}$ Çukurova Üniversitesi Tip Fakültesi, Radyoloji Anabilim Dalı, ${ }^{2}$ Genel Cerrahi Anabilim Dalı, Adana, Turkey
}

\begin{abstract}
Cukurova Medical Journal
Abstract

Purpose: The aim of this study was to investigate the effects of downstaging and bridging treatments on posttransplant survival time in patients with underwent cadaveric liver transplantation hepatocellular carcinoma. Materials and Methods: 33 patients with hepatocellular carcinoma were included in our study. These patients were divided into three groups as downstagning, bridging and control. While trans-arterial chemo-embolization, trans-arterial radio-embolization, radiofrequency ablation or microwave ablation treatments were applied to the bridging and downstaging groups before transplantation, no treatment was applied to the control group. KaplanMeier life analysis was used to calculate survival time after transplantation.
\end{abstract}

Results: The mean follow-up time was $37.5 \pm 32.1$ months. The overall survival rate was $48.5 \%$. The highest survival rates were in the bridging group (54.5\%), then in the control group $(50.0 \%)$ and the lowest survival rate was in the downstaging group (41.7\%). Although there were differences between the groups, statistically significant results could not be obtained.

Conclusion: In this study, it has been concluded that bridging and downstaging methods are effective strategies to keep the patients who will be transplanted with in the Milan Criteria, and survival time in some patients with downstaging group is higher than the average.

Keywords: Bridging treatment, downstaging treatment, hepatocellular carcinoma, transplantation.
Öz

Amaç: $\mathrm{Bu}$ çalışmanın amacı kadaverik karaciğger transplantasyonu yapılmış hepatosellüler karsinomalı hastalarda downstaging ve bridging tedavilerinin transplantasyon sonrası sağ kalım süreleri üzerine etkilerini araştırmaktır.

Gereç ve Yöntem: Çalışmamıza hepatosellüler karsinoma tanısı almış ve kadaverik karaciğer transplantasyonu yapılmış 33 hasta dahil edilmiștir. Bu hastalar downstaging, bridging ve kontrol olmak üzere 3 gruba ayrılmıştır. Bridging ve downstaging gruplarına transplantasyon öncesi transarteriyal kemo-embolizasyon, transarteriyal radyo-embolizasyon, radyofrekans ablasyon veya mikrodalga ablasyon tedavileri uygulanırken kontrol grubuna herhangi bir tedavi uygulanmadi. Transplantasyon sonrası sağ kalım süreleri hesaplanırken Kaplan-Meier yaşam analizi kullanıldı.

Bulgular: Ortalama takip süresi 37,5 $\pm 32,1$ ay olarak hesapland1. Genel sağ kalım oranı \%48,5 idi. En yüksek sağ kalım oranı bridging grubunda $(\% 54,5)$, daha sonra kontrol grubunda $(\% 50,0)$ ve en düşük olarak $(\% 41,7)$ downstaging grubunda olduğu tespit edildi. Her ne kadar gruplar arasinda farklilıklar olsa da istatistiksel olarak anlamlı sonuçlar elde edilemedi.

Sonuç: $\mathrm{Bu}$ çalıșma ile bridging ve downstaging yöntemlerinin transplantasyon yapılacak hepatosellüler karsinomalı hastaları Milan Kriterleri içinde tutmaya yarayan etkili staratejiler olduğu, downstaging yöntemi uygulanan bazı hastalarda sağ kalım sürelerinin ortalamanın üstüne çıktığ1 sonucu elde edilmiştir.

Anahtar kelimeler: Bridging tedavi, downstaging tedavi, hepatosellüler karsinoma, transplantasyon.

Yazışma Adresi/Address for Correspondence: Dr. Hüseyin Tuğsan Ballı, Çukurova Üniversitesi Tıp Fakültesi Radyoloji Anabilim Dalı, Adana, Turkey E-mail: tugsanballi@gmail.com

Geliş tarihi/Received: 11.04.2019 Kabul tarihi/Accepted: 12.05.2019 Çevrimçi yayın/Published online: 16.09.2019 


\section{GİRİ̧̧}

Karaciğer transplantasyonu (KT), hepatosellüler karsinoma (HSK) hastaları için hayat kurtarıcı ve iyileştirici bir tedavi yöntemidir. KT HSK hastaları için en iyi ve en uzun süreli sağkalımı sağlayan tedavi yöntemidir ${ }^{1}$.

HSK hastalarında karaciğer transplantasyonunun başarılı olması için KT uygulanacak hastalarda çeşitli kriterler aranmaktadır. Bu kriterler içerisinden en çok kabul gören ve ülkemizde de kadaverik nakillerde referans kabul edilen Milan Kriterleridir ${ }^{2}$. Milan Kriterleri $(\mathrm{MK})$ (1 lezyon $\leq 5 \mathrm{~cm}, 2$ veya 3 lezyon $\leq 3 \mathrm{~cm}$; vasküler invazyon yok)1996'dan beri HSK olan hastaları tanımlamak için yaygın olarak kabul görmektedir. Bu kriterler yapılan kesitsel çalışmalar ile belirlenmiştir ve bu çalışmalarda MK ile belirlenen hastalarda KT sonrası 5 yıllık sağ kalım ve nüks oranları bakımından mükemmel sonuçlar elde edilmiştir ${ }^{3}$. MK sağ kalım ve nüks açısından önemli olmakla birlikte birçok hasta maalesef bu kriterlerin dışında kalmaktadır. MK dışında kalan hastalar kadaverik KT şansını kaybetmekte ve bu da HSK tedavisi için iyileștirici seçeneğin ortadan kalkmasına yol açmaktadır ${ }^{4}$. MK dışında kalmanın en önemli nedenlerinden biri nakil listesinde sıranın gelmesini beklemektir. Bu süre zarfinda karaciğerde yer alan tümörün çapı ve sayısı çoğunlukla artmakta ve hastayı MK dışına çıarmaktadır ${ }^{5}$.

Geliștirilen yeni stratejiler ile HSK hastaları MK içinde tutulmaya çalışılmaktadır. Bridging ve downstaging HSK hastalarını MK içinde tutmayı sağlayan önemli tedavi yöntemleridir ${ }^{5}$. Bridging; KT için listeye girmiş MK'ye uygun hastaların transplantasyon sirası gelene kadar MK'ye uygun olarak kalmasını amaçlamaktadır. Downstaging ise karaciğer tümörlerinde meydana gelen büyüme ile MK dışında kalan hastaların yapılacak tedavi ile yeniden MK'ye uygun olmasinı hedeflemektedir ${ }^{4}$. Her iki yöntem de doğrudan karaciğeri hedef alan, lokal tedavi yöntemleridir. Bu iki yöntemde hastalar belirli kriterler açısından değerlendirilerek uygun tedavi stratejileri belirlenir. Bridging ve downstaging uygulanacak hastalara transarteriyal kemoembolizasyon (TAKE), transarteriyal radyoembolizasyon (TARE), radyofrekans ablasyon (RFA) veya mikrodalga ablasyon (MDA) tedavileri uygulanabilmektedir ${ }^{5}$.

Biz bu çalışmamızda kadaverik KT yapılmış hastalarda, transplantasyon yapılana kadar geçen sürede bridging ve downstaging uyguladığımız hastaların ve herhangi bir tedavi uygulanmamış kontrol grubunun transplantasyon sonrası sağ kalım sürelerini inceledik. Bu çalışma ile HSK hastalarında transplantasyonun başarısı ile bridging ve downstaging tedavileri arasında bir ilişki olup olmadığı hakkında bilgi sahibi olunacaktır.

\section{GEREÇ VE YÖNTEM}

Çalışmamıza 2010 ve 2017 yılları arasında Çukurova Üniversitesi Tip Fakültesi Hastanesinde takibi yapılan, radyolojik ve/veya patolojik olarak HSK tanısı almış ve kadaverik KT yapılmış 33 hasta dahil edildi. Hastalara yapılan tedaviler Çukurova Üniversitesi Tip Fakültesi Eğitim ve Araştırma Hastanesi Girişimsel Radyoloji Ünitelerinde gerçekleştirildi.

Çalışmaya dahil edilen 33 hasta downstaging, bridging ve kontrol olmak üzere 3 gruba ayrildı. Bridging grubunda, MK'ye uygun olan ancak transplantasyon sirası bekleyen 11 hasta yer aldı. Bu grupta yer alan hastalara transplantasyon siras1 beklerken MK dışında kalmamaları için uygun tedaviler uygulandı. MK dișinda kalan 12 hasta downstaging grubuna dahil edildi ve KT yapılacak tarihe kadar MK'ye uygun olmaları için çeşitli tedaviler uyguland. MK'ye uygun olup herhangi bir tedavi yapilmadan KT uygulanan 10 hasta kontrol grubuna dahil edildi. Hastaların tamamı postoperatif olarak radyolojik ve/veya patolojik olarak değerlendirilerek kolanjiyosellüler karsinom gelişmediği tespit edildi ve explante karaciğerde yapılan patolojik değerlendirmede tüm lezyonlar HSK ile uyumlu bulundu.

\section{Downstaging ve Bridging protokolleri}

Hastalara çeşitli alt protokoller uygulandı. Kullanılan tedavilerin türü ve sayıs1, her bir hastaya, tümör özelliklerine ve yanıtlarına göre uyarlandı. Her iki protokolde TAKE, TARE, RFA veya MDA teknikleri kullanıldı. RFAve MDA perkutan yolla uygulandı. Hangi tekniğin kullanılacağı hastaya göre belirlendi. $<3 \mathrm{~cm}$ büyüklügünndeki tümörler için RFA veya MDA uyguland, tümörün boyutu arttıkça,bu yöntemler ile eksik tedavi olasılloğ1 artacağı için daha büyük tümörler için TAKE, TARE veya kombinasyon tedavisi önerildi 6 . Perkütan RFA veya MDA prosedürleri, intravenöz midazolam ve fentanilin titre edilmiş dozları kullanılarak ve ultrason ve/veya bilgisayarlı tomografi rehberliği 
kullanılarak bilinçli sedasyon veya genel anestezi altında gerçekleştirildi.

TAKE işlemleri ise konvansiyonel TAKE (KTAKE) veya ilaç salınımlı partiküllerle TAKE (ISPPTAKE) şeklinde yapıldı.

K-TAKE; lipiodol (Guerbet) bazlı (maks. $10 \mathrm{ml}$ ) kemoterapötik bir ilaçla (epirubisin hidroklorür) yapıldı. K-TAKE standart teknikler kullanılarak yapıld1, $30 \mathrm{mg}$ mitomisin, $30 \mathrm{mg}$ adriamisin ve lipiyodol ile karıştırılmış $100 \mathrm{mg}$ sisplatin uyguland ${ }^{7}$. Daha sonra, kalıcı tıkayıcı parçacıklar kullanılarak embolizasyon yapildı.

İSP-TAKEise; 100-300 mikron ilaç salınımlı embolik mikro küreler kullanarak uygulandı (LC Bead; BTG, London, England). Her uygulamada ortalama 50-75 mg doksorubisin dozu kullanıldı.

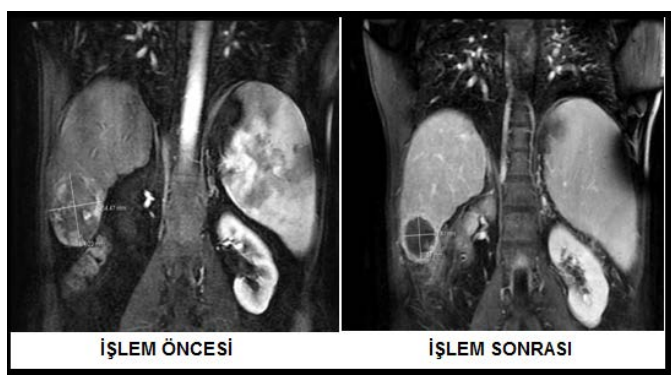

Şekil 1:Downstaging uygulaması yapılmadan önce ve sonrasında tümör büyüklüğ̈nde meydana gelen değişiklik (Önceki boyut:54,47 mm X 64,22 mm, İșlem sonrası boyut: $34,41 \mathrm{~mm}$ X $37,57 \mathrm{~mm}$ )

Anjiyografi tüm hastalarda transfemoral bir yaklaşımla gerçekleştirildi. Hepatik ve tümörü besleyen arterlerin süper selektif kateterizasyonundan sonra K-TAKE veya İSPTAKE yöntemlerinden birisi kullanılarak HSK lezyonunda veya tümör besleme alanında staz oluşturuldu. Gerekli durumlarda tümörde tam staz elde etmek için kalibre edilmiş polivinil alkol partikülleri (BeadBlock; Biocompatibles International, Farnham, UK) veya diğer mikroküreler (Embozene; CelonovaBiosciences, Atlanta, Ga., ABD) uygulandi. Hastalar tüm prosedür boyunca dikkatlice gözlendi, analjezikler ve antiemetikler talep üzerine verildi.

MDA, 915veya $2450 \mathrm{MHz}$ jeneratör özelliklerine sahip ticari olarak temin edilen bir sistemle (Evident MW Ablasyon Sistemi, Covidien, Boulder, CO, ABD), (EMprint ve MicrothermX) ultrasonografi veya cone-beam bilgisayarli tomografi kılavuzluğunda gerçekleştirildi. Hedef tümörde yeterli koagülasyon nekrozunu ve $1 \mathrm{~cm}$ 'lik doku marjını sağlamak esas alındı.

\section{İstatistiksel analiz}

Çalışmada kategorik değişkenler özetlenirken n (\%), sürekli değişkenler olan ortalama takip süresi özetlenirken ise ortalama \pm standart sapma (minimum değer - maksimum değer) kullanıldı. Yaşam sürelerinin hesaplanmasinda KaplanMeieryaşam analizi uyguland. Gruplarda yaşam sürelerini karşılaştırırken Log-rank testi kullanıldı. Yaşam süreleri ile ilgili tanımlayıcı istatistikler ise ortalama \pm standart hata değerleri ile sunuldu ve hesaplanması mümkün olan yerlerde (sağkalım oranı $<\% 50$ olan) medyan değerler de verildi. $\mathrm{p}<0,05$ olan durumlar istatistiksel olarak anlamlı kabul edildi. Verilerin analizinde IBM SPSS ver. 19 paket programı kullanıldı (IBM Corp. Released 2010. IBM SPSS Statisticsfor Windows, Version19.0. Armonk, NY: IBM Corp.).

Tablo 1. Downstaging grubuna dahil edilen hastaların yaş ve lezyon bilgilerine ait tablo.

\begin{tabular}{|l|c|c|c|}
\hline $\begin{array}{l}\text { Hasta } \\
\text { No }\end{array}$ & $\begin{array}{l}\text { Hastanın } \\
\text { Transplantasyon } \\
\text { Sirasındaki Yaş1 }\end{array}$ & $\begin{array}{l}\text { İşlem } \\
\text { Öncesi } \\
\text { Lezyon } \\
\text { Boyutu } \\
\text { (cm) }\end{array}$ & $\begin{array}{l}\text { (̇şlem } \\
\text { Öncesi } \\
\text { Lezyon } \\
\text { Sayıs1 }\end{array}$ \\
\hline 1 & 55 & 2 & 1 \\
\hline 2 & 51 & 5 & 1 \\
\hline 3 & 56 & 3.5 & 3 \\
\hline 4 & 55 & 6 & 2 \\
\hline 5 & 56 & 5 & 2 \\
\hline 6 & 58 & 8.5 & 1 \\
\hline 7 & 65 & 5.5 & 1 \\
\hline 8 & 66 & 6 & 1 \\
\hline 9 & 62 & 2 & 4 \\
\hline 10 & 53 & 6 & 1 \\
\hline 11 & 63 & 7 & 1 \\
\hline 12 & 43 & 4 & 3 \\
\hline Ortalama & 56.91 & 5.04 & 1.75 \\
\hline
\end{tabular}

*: Lezyon sayıs 1'den fazla olan hastalarda en büyük lezyona ait değer paylaşılmışıtır.

\section{BULGULAR}

Çalışmada bridging grubunda 11 (\%33,3), downstaging grubunda $12(\% 36,4)$ ve kontrol grubunda $10 \quad(\% 30,4)$ olmak üzere toplamda 33 hasta değerlendirilmiştir. Bu 33 hastadan yalnızca 3'ü $(\% 9,0)$ kadın 30’u $(\% 90,9)$ erkektir ve çalışmaya alınan 3 kadin hasta downstaging grubunda bulunmaktaydi. Bridging grubunda yer alan 
hastaların yaş ortalaması 56,91, işlem öncesi lezyon boyut ortalaması $5,04 \mathrm{~cm}$ ve işlem öncesi lezyon sayılarının ortalaması 1,75 olarak hesaplandı (Tablo 1). Downstaing grubunda yer alan hastaların yaş ortalaması 55,63, işlem öncesi lezyon boyut ortalaması $3,13 \mathrm{~cm}$ ve işlem öncesi lezyon sayılarının ortalamas1 1,09 olarak hesaplandı (Tablo 2). Kontrol grubunda yer alan hastaların yaş ortalaması 53,90, işlem öncesi lezyon boyut ortalaması $2,95 \mathrm{~cm}$ ve işlem öncesi lezyon sayılarının ortalaması 1,72 olarak hesapland1 (Tablo 3).

Ortalama takip süresi $37,5 \pm 32,1$ ay olarak hesapland1 (min:0,1 - maks: 112). Çalışmada bu takip süresi boyunca 17 hasta ölmüştür $(\% 51,5)$. Genel sağ kalım oranı ise \%48,5 idi. En yüksek sağ kalım oranı bridging grubunda $(\% 54,5)$, daha sonra kontrol grubunda $(\% 50,0)$ ve en düşük olarak $(\% 41,7)$ downstaging grubundaydı. Kaplan-Meier sağkalım analizi sonucunda 33 hastanın ortalama sağ kalım

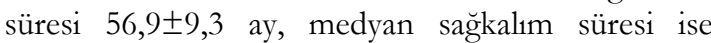
43,1 $\pm 19,4$ ay olarak bulundu. Çalışma gruplarında toplam să̆ kalım durumları incelendiğinde LogRank testi sonucunda grupların yaşam süreleri arasında istatistiksel olarak anlamlı farklılığa rastlanmamıstır $(p=0,861)$. Bridging grubunda ortalama yaşam süresi $51,2 \pm 13,5$ ay iken downstaging grubunda ortalama yaşam süresi $50,7 \pm$ 15,1 ay ve kontrol grubunda 47,9 $\pm 10,9$ ay olarak bulunmuştur.

Tablo 2. Bridging grubuna dahil edilen hastaların yaş ve lezyon bilgilerine ait tablo

\begin{tabular}{|l|l|l|l|}
\hline $\begin{array}{l}\text { Hasta } \\
\text { No }\end{array}$ & $\begin{array}{l}\text { Hastanın } \\
\text { Transplantasyon } \\
\text { Sırasındaki Yaş1 }\end{array}$ & $\begin{array}{l}\text { İslem } \\
\text { Öncesi } \\
\text { Lezyon } \\
\text { Boyutu } \\
\text { (cm)* }\end{array}$ & $\begin{array}{l}\text { İşlem } \\
\text { Öncesi } \\
\text { Lezyon } \\
\text { Sayısis }\end{array}$ \\
\hline 1 & 56 & 2.5 & 1 \\
\hline 2 & 44 & 4.5 & 1 \\
\hline 3 & 61 & 3 & 1 \\
\hline 4 & 62 & 2.5 & 1 \\
\hline 5 & 58 & 4 & 1 \\
\hline 6 & 59 & 4 & 1 \\
\hline 7 & 44 & 2 & 1 \\
\hline 8 & 55 & 4 & 1 \\
\hline 9 & 59 & 2.5 & 1 \\
\hline 10 & 55 & 2 & 2 \\
\hline 11 & 59 & 3.5 & 1 \\
\hline Ortalama & 55.63 & 3.13 & 1.09 \\
\hline
\end{tabular}

*: Lezyon sayısı 1'den fazla olan hastalarda en büyük lezyona ait değer paylaşılmıştır.
Medyan yaşam süreleri incelendiğinde bridging grubunda bu süre hesaplanamazken, downstaging grubunda medyan yaşam süresi $10,2 \pm 17,8$ ay kontrol grubunda ise medyan yaşam süresi 45,2 \pm 2,6 ay olarak bulunmuştur. Medyan yaşam sürelerindeki bu ciddi farklılık downstaging grubunda hastaların yarısının çok kısa sürede ölmesinden kaynaklanmaktadır (Grafik 1). Cerrahi komplikasyon ve/veya teknik komplikasyonlara bağlı ölümler sebebiyle kaybedilen hastalar çıkarıldıktan sonra genel sağ kalım süreleri; kontrol grubunun minumum sağ kalım süresi 8 ay, maksimum sağ kalım süresi 80 ay, downstaging grubunda minumum sağ kalım süresi 10 ay, maksimum să̆ kalım süresi 110 ay olarak hesaplanırken bridging grubunda hasta kaybinın fazla olması sebebiyle bu değer hesaplanamadı. Tüm grupların ortalama sağ kalım süresi 42 aydı. Toplam sağ kalım durumları incelendiğinde Log-Rank testi sonucunda grupların yaşam süreleri arasında istatistiksel olarak anlamlı farklılığa rastlanmamıştır $(\mathrm{p}=0,647)$ (Grafik 2).

Tablo 3. Kontrol grubuna dahil edilen hastaların yaş ve lezyon bilgilerine ait tablo.

\begin{tabular}{|l|l|l|l|}
\hline $\begin{array}{l}\text { Hasta } \\
\text { No }\end{array}$ & $\begin{array}{c}\text { Hastanın } \\
\text { Transplantasyon } \\
\text { Sirasındaki Yaşi }\end{array}$ & $\begin{array}{c}\text { İşlem } \\
\text { Oncesi } \\
\text { Lezyon } \\
\text { Boyutu } \\
(\mathrm{cm})^{*}\end{array}$ & $\begin{array}{c}\text { İslem } \\
\text { Öncesi } \\
\text { Lezyon } \\
\text { Sayıs }\end{array}$ \\
\hline 1 & 56 & 6 & 2 \\
\hline 2 & 45 & 5,5 & 4 \\
\hline 3 & 63 & 5 & 1 \\
\hline 4 & 55 & 3 & 1 \\
\hline 5 & 49 & 2 & 1 \\
\hline 6 & 60 & 2 & 3 \\
\hline 7 & 50 & 2 & 1 \\
\hline 8 & 59 & 2 & 3 \\
\hline 9 & 48 & 2 & 1 \\
\hline 10 & 52 & 1 & 1 \\
\hline 11 & 53 & 2 & 1 \\
\hline Ortalama & 53,90 & 2,95 & 1,72 \\
\hline
\end{tabular}

*: Lezyon say1sı 1'den fazla olan hastalarda en büyük lezyona ait değer paylaşılmıştır.

Sağ kalımın yıllara göre gruplardaki dağılımı yıllara göre karşılaştırıldığında, 1. yılsonunda bridging ve downstaing gruplarında sağkalım oranı \%27,27 iken kontrol grubunda \%21,21 olarak tespit edildi. 3 . yılsonunda bridging grubunda sağ kalım oranı $\% 15,5$, downstaing grubunda $\% 21,21$ ve kontrol grubunda \%18,18 olarak tespit edildi. 5.y1lsonunda bridging grubunda sağkalım oranı $\% 9,1$, downstaing 
grubunda $\% 15,15$ ve kontrol grubunda $\% 9,1$ olarak tespit edildi (Tablo 4).

Tablo 4. Yıllara göre să̆ kalım oranlarının gruplar arasında karşılaştırılması

\begin{tabular}{|l|c|c|c|}
\hline & $\mathbf{1 . Y 1 l}$ & $\mathbf{3 . Y 1 l}$ & $\mathbf{5 . Y 1 l}$ \\
\hline Bridging & $\% 27.27$ & $\% 15.15$ & $\% 9.1$ \\
\hline Downstaging & $\% 27.27$ & $\% 21.21$ & $\% 15.15$ \\
\hline İşlemsiz Grup & $\% 21.21$ & $\% 18.18$ & $\% 9.1$ \\
\hline
\end{tabular}

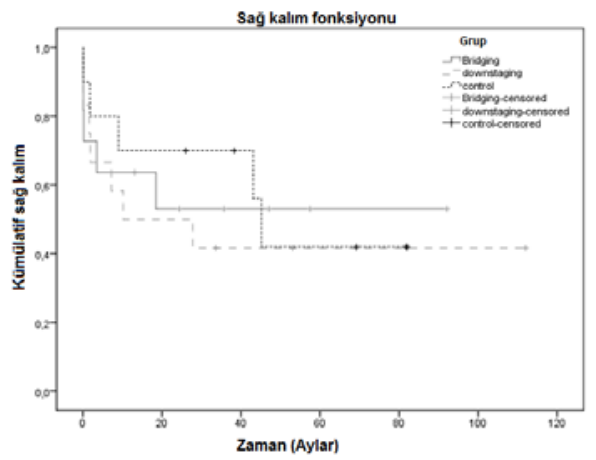

Grafik 1. Bridging, downstaging ve kontrol gruplarında medyan yaşam sürelerinin karşıllaştırılması.

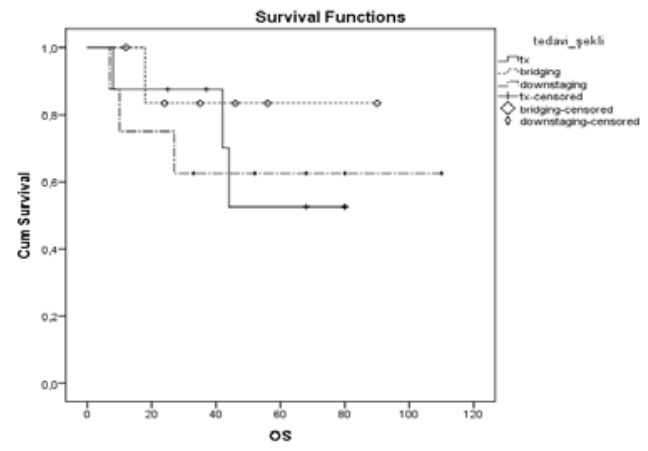

Grafik 2. Bridging, downstaging ve kontrol gruplarından komplikasyona bağlı ölümler nedeniyle kaybedilen hastalar çıkarıldıktan sonra medyan yaşam sürelerinin karşılaştırılması.

\section{TARTIŞMA}

Karaciğer transplantasyonu, hepatosellüler karsinomalı hastalar için hayat kurtarıcı ve iyileştirici bir tedavi yöntemidir. KT HSK hastaları için en iyi ve en uzun süreli sağ kalımı sağlayan tedavi yöntemidir ${ }^{1}$.

Bir hastanın ülkemizde kadaverik KT ye uygun olup olmadığ1 MK ile belirlenir ${ }^{8}$. Transplantasyona uygun olmak hastalar için umut verici olsa da bu hastaların transplantasyon sırası gelinceye kadarliste dişında kalmaması ve mevcut uygunluğunu koruması gerekmektedir. Ancak çoğu zaman HSK progresyonu sebebiyle hastaların uzun süreler boyunca MK'ye uygun olması imkansızlaşmaktadır?. Gelisstirilen yeni stratejiler ile HSK hastaları MK içinde tutulmaya çalışılmaktadır. Bridging ve downstaging işlemleri HSK hastalarını MK içinde tutmay1 sağlayan önemli tedavi yöntemleridir ${ }^{5}$. Bridging; KT için listeye girmiş MK'ye uygun hastalarin transplantasyon sirası gelinceye kadar MK ye uygun olarak kalmasını amaçlamaktadır. Downstaging ise karaciğer tümörlerinde meydana gelen büyüme ile $\mathrm{MK}$ dışında kalan hastaların yapılacak tedaviler ile yeniden $\mathrm{MK}$ ye uygun olmasinı hedeflemektedir ${ }^{4}$.

Son yıllarda bu yöntemler ile KT'nin başarılı olması ve yaşam süresine etkisi ile ilgili birçok çalışma yapılmaktadır. Ancak organ bağışlarının yeterli olmamas1, uygun hastaların bulunamamas1 gibi nedenler transplantasyon rakamlarının çok düşük olmasına yol açmaktadır. Bunun sonucu olarak bu tarz çalışmalarda örneklem büyüklüğü sınırlı kalmaktadır. 2013 yllinda downstaging tedavisinin KT sonrası sağkalım üzerine etkisini araştıran Green ve ark 7 hastaya, Thome ve ark 8 hastaya, Bova ve ark 9 hastaya çalışmalarında yer verebilmiştir ${ }^{10-12}$. Çalışmamızda bridging grubunda 11 (\%33,3), downstaging grubunda $12(\% 36,4)$ ve kontrol grubunda $10 \quad(\% 30,4)$ olmak üzere toplamda 33 hasta değerlendirilmiştir. $\mathrm{Bu}$ veriler tek başına değerlendirildiğinde örneklem gruplarımız küçük görünse de yapılmış diğer çalışmalar ile kıyaslandığında bu rakamların anlamlı olduğu sonucuna ulaşılabilir. Çalışmaya dahil edilen hastaların ortalama takip süreleri 2010 yilında yapılan bir çalışmada 29,3 ay iken 2009 yılında farklı bir çalışmada 36,5 ve 2008 y1lında Chapman ve ark'larının yaptığı çalışmada 27,5 olarak bildirilmiştir ${ }^{2,12,13}$. Çalışmamızda hastalarımızın 
ortalama takip süresi 37,5 aydır. Bu süre literatürdeki çalışmalarla benzer sonuçları kapsamaktadır.

KT yapılmış hastalarda sağ kalım oranları incelendiğinde literatürde oldukça farklı değerler olduğu görülmektedir. Bridging uygulanmış hastalarda yapılan çalışmalarda Alba ve ark să̆ kalım oraninı \%60.4, Branco ve ark \%67,7 ve Brillet ve ark ise $\% 69$ olarak vermiștir ${ }^{14-16}$. Biz çalıșmamızda en yüksek sağ kalım oranı bridging grubunda elde ettik ve bu oran \%54,5' tir. Elde ettiğimiz değer benzer diğer çalışmalardan daha düşük olmakla birlikte büyük farklılık içermemektedir. Downstaging uygulanmış hastalarda sağ kalım oranları Grazidei ve ark tarafindan \%41, Jang ve ark tarafindan \%54.6 olarak verilmiştir ${ }^{5,17}$. Biz çalışmamızda downstagning grubunda sağ kalım oranını \%41.7 olarak belirledik. Bu değer benzer çalışmalarda elde edilen sonuçların biraz altında kalmaktadır. Kontrol grubunda elde ettiğimiz sağ kalım oranı ise $\% 50$,0dir.

Bridging grubu ortalama yaşam süreleri bakımından kıyaslandığında önceki çalışmalarda $\mathrm{Lu}$ ve ark ortalama 36 ay, Alba ve ark 60 ay, Hayashi ve ark 48 ay sonuçlarını paylaşmışlardır ${ }^{5,14,18}$. Biz de çalışmamızda bridging grubunda ortalama yaşam süresini 51,2 ay olarak hesapladık. Downstaging grubunda ortalama yaşam süresi ile ilgili yapılmış çalışmalarda Cillo ve ark ile De Luna ve ark 36 ay, Otto ve ark 48 ay değerlerini elde etmiştir ${ }^{19-21}$. Biz çalışmamızda downstaging grubunda ortalama yaşam süresini 50,7 ay, kontrol grubunda 47,9 ay ve 33 hastanın ortalama sağ kalım süresini 56,9 ay olarak bulduk. Downstaging grubunda elde ettiğimiz sağ kalım süresi literatürdeki birçok çalıșmadan daha uzundur. Bu farklilik anlamlı derece de olmasa da downstaging uygulamaları konusunda umut vericidir.

Hastaları gruplar içinde tek tek incelediğimizde en uzun sağ kalım süresinin downstaging grubunda yer alan hastalarda olduğu görüldü. Ancak bu grupta yer alan hastalardan bazılarının erken kayıpları istatistiksel olarak elde edilen ortalamaların düșük çıkmasına yol açtı. Bu tedavi stratejilerinin bazı hastalarda çok iyi sonuçlar vermesinin bazılarında ise tedaviye cevabın çok az olmasının bireysel farklılıklar ile alakalı olabileceğini düşünmekteyiz. $\mathrm{Bu}$ alanda yapılacak çalışmalarda uygulanacak tedavi stratejilerinin belirlenmesinde sadece biyokimyasalbelirteçler, tümör çap1 ve evresi gibi kriterlerin yeterli olmayacağına inanmaktayız. Hastalara ait genetik farklılıkların göz önünde bulundurulması ve bu konuda ek çalışmaların yapılmas1 transplantasyon tedavilerine önemli katkılar sağlayacağını düşünmekteyiz. Bununla birlikte bu yöntemler ile yapılacak çalışmalarla sadece transplantasyona uygunluğu sağlamanın dışında belki de HSK'de tam bir iyileşmeyi sağlayacak tedavi stratejileri geliştirilebilir. Downstaging yapılarak MK içerisine sokulan hasta grubunda uygun ve 1 lımlı biyolojiye sahip tümörler taşıyan hastaların bulunduğuna inanmaktayız. Nakil sonrası sağ kalım sürelerinde olumlu değişikliler olan downstaging tedavisi görmüş hastalar bu görüşümüzü destekleyen güçlü bir belirteçtir. Bu nedenle downstaging protokolü uygulanan hastalarda, hasta MK içerisine sokulduktan sonra bazı gruplara göre 3 ay bazı gruplara göre 6 ay gibi bir bekleme süresi takip edildikten sonra hastada eğer bir progresyon yok ise nakil kararının verilmesi gerekmektedir.Örneklem büyüklüğünün az olmas1 çalışmamızı sınırlandıran en önemli faktördür.

$\mathrm{Bu}$ çalışma bridging ve downstaging yöntemlerinin transplantasyon yapılacak hastaları MK içinde tutmaya yarayan etkili stratejiler olduğu, downstaging yöntemi uygulanan bazı hastalarda sağ kalım sürelerinin ortalamanın üstüne çıktığı sonucu elde edilmiştir.

Yazar Katkıları: Calısma konsepti/Tasarımı: HTB, AÜ; Veri toplama: HTB, AÜ; Veri analizi ve yorumlama: HTB, AÜ; Yazı taslağı: HTB İçeriğin eleştirel incelenmesi: HTB, AÜ; Son onay ve sorumluluk: HTB, AÜ; Teknik ve malzeme desteği: -; Süpervizyon: HTB, AÜ; Fon sağlama (mevcut ise): yok.

Bilgilendirilmiş Onam: Katılımcılardan yazılı onam alınmıștır.

Hakem Değerlendirmesi: Dış bağımsız.

Çıkar Çatışması: Yazarlar çıkar çatıșması beyan etmemișlerdir. Finansal Destek: Yazarlar finansal destek beyan etmemişlerdir. Author Contributions: Concept/Design : HTB, AÜ; Data acquisition: HTB, AÜ; Data analysis and interpretation: HTB, AÜ; Drafting manuscript: HTB; Critical revision of manuscript: HTB, AÜ; Final approval and accountability: HTB, AÜ; Technical or material support: -; Supervision: HTB, AÜ; Securing funding (if available): n/a. Informed Consent: Written consent was obtained from the participants.

Peer-review: Externally peer-reviewed.

Conflict of Interest: Authors declared no conflict of interest.

Financial Disclosure: Authors declared no financial support

\section{KAYNAKLAR}

1. Parikh ND, Waljee AK, Amit G. Singal, downstaging hepatocellular carcinoma:a systematic reviewand pooled analysis. Liver Transpl 2015:21:1142-52.

2. Mazzaferro V, Llovet J, Miceli R, Bhoori S, Schiavo M, Mariani L et al. Predicting survival after liver transplantation in patients with hepatocellular carcinoma beyond the Milan criteria: a retrospective, exploratory analysis. Lancet Oncol. 2009;10:35-43.

3. Sandri G.B., Rayar M, Qi X andLucatelli P. Liver transplant for patients outside Milan criteria. Transl Gastroenterol Hepatol. 2018;3:81. 
4. Rudnick SP, Russo MW. Liver transplantation beyond or downstaging with in the Milan criteria for hepatocellular carcinoma. Expert Rev Gastroenterol Hepatol. 2018;265-275.

5. Pompili M, Francica G, Ponziani FR, Iezzi R, Avolio AW. Bridging and downstaging treatments for hepatocellularcarcinoma in patients on the waiting list for liver transplantation. World J Gastroenterol. 2013;19:7515-30.

6. Pomfret EA, Washburn K, Wald C, Nalesnik MA, Douglas D, Russo M et al. Report of a national conference on liveral location in patients with hepatocellular carcinoma in the United States. Liver Transpl. 2010;16:262-78.

7. Lewandowski RJ, Kulik LM, Riaz A, Senthilnathan S, Mulcahy MF et al. A comparative analysis of transarterial downstaging for hepatocellular carcinoma: chemoembolization versus radio embolization. Am J Transplant 2009;9:1920-8.

8. Mennon KV, Hakeem AR, Heaton ND. Review article: liver transplantation for hepatocellular carcinoma - a critical appraisal of the current worldwide listing criteria. Aliment Pharmacol Ther. 2014;40:893-902.

9. El-Serag HB, Siegel AB, Davila JA, Shaib YH, Cayton-Woody M, McBride R et al. Treatment and outcomes of treating of hepatocellular carcinoma among Medicare recipients in the United States: a population based study. J Hepatol. 2006;44:158-66.

10. Green TJ, Rochon PJ, Chang S, Ray CE Jr, Winston $\mathrm{H}$, Ruef $\mathrm{R}$ et al. Downstaging disease in patients with hepatocellular carcinoma outside of Milan criteria: strategies using drug-eluting bead chemoembolization. J Vasc Interv Radiol 2013;24:1613-22.

11. Tohme S, Sukato D, Chen HW, Amesur N, Zajko AB, Humar A et al. Yttrium-90 radioembolization as a bridge to liver transplantation: a single-institution experience. J Vasc Interv Radiol 2013;24:1632-8.

12. Bova V, Miraglia R, Maruzzelli L, Vizzini GB, Luca A. Predictive factors of downstaging of hepatocellular carcinoma beyond the Milan criteria treated within tra-arterial therapies. Cardiovasc Intervent Radiol. 2013;36:433-9.

13. Chapman WC, MajellaDoyle MB, Stuart JE,
Vachharajani N, Crippin JS et al. Outcomes of neo adjuvant trans arterial chemo embolization to down stage hepatocellular carcinoma before liver transplantation. Ann Surg. 2008;248:617-25.

14. Alba E, Valls C, Dominguez J, Martinez L, Escalante E, Lladó $\mathrm{L}$ et al. Trans catheter arterial chemoembolization in patients with hepatocellular carcinoma on the waiting list for orthotopic liver transplantation. AJR Am J Roentgenol 2008;190:1341-8

15. Branco F, Brú C, Vilana R, Bianchi L, Alves de Mattos A. Percutaneouse than olinjection before liver transplantation in the hepatocellular carcinoma. Ann Hepatol. 2009;8:220-7.

16. Brillet PY, Paradis V, Brancatelli G, Rangheard AS, Consigny $\mathrm{Y}$, Plessier A et al. Percutaneous radio frequency ablation for hepatocellular carcinoma before liver transplantation: a prospective study with histopathologic comparison. AJR Am J Roentgenol 2006;186:296-305.

17. Graziadei IW, Sandmueller H, Waldenberger P, Koenigsrainer A, Nachbaur K, Jaschke W et al. Chemoembolization followed by liver transplantation for hepatocellular carcinoma impedes tumor progression while on the waiting list and leads to excellent outcome. Liver Transpl. 2003;9:557-63.

18. Hayashi PH, Ludkowski M, Forman LM, Osgood M, Johnson S, Kugelmas $M$ et al. Hepatic artery chemoembolization for hepatocellular carcinoma in patients listed for liver transplantation. Am J Transplant. 2004;4:782-7.

19. Cillo U, Vitale A, Volk ML, Frigo AC, Grigoletto F, Brolese A et al. The survival benefit of liver transplantation in hepatocellular carcinoma patients. Dig Liver Dis. 2010;42:642-9.

20. De Luna W, Sze DY, Ahmed A, Ha BY, Ayoub W, Keeffe EB et al. Transarterial chemoinfusion for hepatocellular carcinoma as downstaging therapy and a bridge to ward liver transplantation. Am J Transplant. 2009;9:1158-68.

21. Otto G, Herber S, Heise M, Lohse AW, Mönch C, Bittinger $\mathrm{F}$ et al. Response to trans arterial chemoembolization as a biological selection criteri on for liver transplantation in hepatocellular carcinoma. Liver Transpl 2006;12:1260-7. 